\section{Oral morbidity and associated factors in Chilean preschoolers and schoolchildren: A preliminary review.}

\author{
Ángela $\operatorname{Arias}^{1} \&$ Lorena Fuentes ${ }^{1}$.
}

Abstract: Currently, the most prevalent oral pathologies in Chile are dental caries, periodontal diseases, and dentomaxillary anomalies, with dental caries being considered the most prevalent in childhood and a public health problem. In Chile, research on and diagnosis of these diseases in preschoolers and schoolchildren are varied over time, but there is no review of the existing studies relating these pathologies to the most common risk factors, such as socioeconomic level, rurality, and nutritional status. The objective of this preliminary review is to assess oral morbidity in preschoolers and schoolchildren associated with risk factors in Chile. A national study found that the prevalence of caries is $16.8 \%$ at two years, $49.6 \%$ at four years, $70.4 \%$ at six years, $62.5 \%$ at 12 years, and $73.9 \%$ at 15 years. In relation to the severity of caries, it found a DMFT of 0.5 at two years, a DMFT of 2.3 at 4 years, and a DMFT of 3.7 at six years in temporary dentition. In permanent dentition, that the same study found a DMFT of 0.15 at six years, a DMFT of 1.9 at 12 years, and a DMFT of 3.0 at 15 years. Regarding gingivitis, it found a prevalence of $32.6 \%$ at two years, $45 \%$ at four years, $55.1 \%$ at six years, and $66.9 \%$ at 12 years. As for dentomaxillary anomalies, $33.3 \%$ presented some degree of anomaly at four years, $38.3 \%$ at six years, and $53 \%$ at 12 years. Despite the above, there are various studies in specific localities that have found a higher prevalence and severity of oral diseases. However, it is necessary to carry out a systematic evaluation to determine the prevalence and severity for each of the most prevalent oral diseases, as well as to identify the risk factors for the incidence of said diseases.

Keywords; oral hygiene, preschoolers, schoolchildren, Chile, risk factors

\section{INTRODUCTION}

Nowadays, oral diseases are a public health problem, due to their high prevalence and impact on quality of life. The most prevalent oral diseases in the world, including Chile, are dental caries, gingival diseases, and dentomaxillary anomalies, which begin early in life and increase over the years (Ministerio de Salud, 2010).

Dental caries are a disease of multifactorial origin, in which enamel demineralization occurs. According to the World Health Organization (WHO), there are currently between $60 \%$ and $90 \%$ of children with caries. The growth and development of the jaws, and therefore the occlusion, can be altered by multiple factors that determine the appearance of dentomaxillary anomalies. Among these factors are genetic predisposition and environmental factors, such as bad habits and alterations in the functions of the stomatognathic system (Petersen et al., 2005).

In Chile, there are several research studies involving the prevalence of caries, gingivitis, and dentomaxillary anomalies in the preschool and school-age population. These studies are also related
INT J MED

SURG SCI

Affiliations: 'Facultad de Odontología, Universidad Andrés Bello, Concepción, Chile.

Corresponding author: Ángela

Arias. Dirección: Lago de la Laja \#2207 Villa Doña Graciela Coronel. Phone: +569 955632495 +56412718524. E-mail: angela.a.panes@gmail.com.

$\begin{array}{ll}\text { Receipt: } & 04 / 11 / 2018 \\ \text { Revised: } & 04 / 16 / 2018 \\ \text { Acceptance: } & 05 / 07 / 2018 \\ \text { Online: } & 08 / 30 / 2018\end{array}$

Conflict of interests: None.

Ethics approval: Not required.

Funding: None.

Authors' contributions: All authors carried out the entire review.

Acknowledgements: None.

doi: $10.32457 / \mathrm{ijmss.2018.008}$. 
to different variables and risk factors, of which we can highlight the socioeconomic level, level of rurality, and nutritional status. The objective of this preliminary review is to evaluate the oral morbidity in preschoolers and schoolchildren associated with risk factors in Chile.

\section{EVIDENCE IN CHILEAN PRESCHOOLERS AND SCHOOLCHILDREN}

There is an association between caries and socioeconomic level, level of rurality, and malnutrition. In the case of preschoolers, Zaror et al. (2011) conducted a cross-sectional study to determine the prevalence of early childhood caries (ECC) and severe early childhood caries (S-ECC) in 301 children and their relationship with socio-demographic factors as well as dietary and oral hygiene habits. The prevalence was $70 \%$ for ECC and $52 \%$ for S-ECC, finding a statistically significant association between ECC and age, rurality, and nutritional status.

In another study, Espinoza-Espinoza et al. (2016) compared the prevalence of ECC in rural areas where water is not fluoridated, controlling for risk factors such as oral hygiene and the type of health forecast, finding a high association between these risk factors and ECC. To this end, they evaluated 587 children aged two and three who belong to non-fluoridated rural areas of Chile in rural nurseries located in non-fluoridated areas in La Araucanía, Los Ríos, and Los Lagos regions, Chile. The prevalence of ECC was $51.62 \%$, with an average DMFT index of 2.53. The Region of La Araucanía had the highest prevalence of ECC (52.79\%). The variables that showed association were age, $\mathrm{S}-\mathrm{OHI}$, and type of health insurance $(\mathrm{p}<0.05)$. The authors concluded that there is a higher prevalence of ECC in areas with a non-fluoridated water supply, which, in turn, is associated with the level of rurality.

Regarding the association between ECC and nutritional status, Zaror et al. (2014) performed an observational retrospective cohort study on 196 two-yearold children from the Calbuco Hospital admitted for dental treatment during the years 2007 to 2009 in order to evaluate the association between malnutrition due to excess and ECC. They found that $33.67 \%$ of the sample was overweight at the beginning of the cohort and $16.33 \%$ were obese, reaching $40 \%$ overweight and $20.56 \%$ obese at four years of age. The incidence of ECC in children with malnutrition by excess was $57.14 \%$ in relation to $40.82 \%$ of eutrophic children ( $p=0.022)$ with RR of $1.4(95 \% \mathrm{Cl} 1044-1,88)$. Therefore, there is an increased risk associated with ECC in patients with malnutrition due to excess.

Zaror et al. (2012) also conducted a study on a sample of 102 four-year-old children. A dental examination was performed, determining the presence of visible bacterial plaque, dental caries, and gingival bleeding. The results showed a prevalence of $93.1 \%$ gingivitis. When performing the analysis of the correlation of gingivitis with other factors, a positive correlation was found only with caries and with the level of bacterial plaque by sextant. Therefore, considering the high prevalence found, the most affected sextants, and the scarce relationship with data from the anamnesis of the child, all these data should be considered in the education given to the adult.

The previous results coincide with the study by Bravo etal. (2010), who also carried out a study concerning malnutrition. The authors found that excess malnutrition could be an indicator for caries in preschoolers. The DMFT and oral hygiene indexes were measured according to gender, analyzing the frequency of brushing and diet. An oral examination was performed, with development of bacterial plaque, dietary survey, and record of the frequency of brushing. The DMFT index was 2.67 (SD \pm 1.87) for boys and 5.1 (SD \pm 2.64$)$ for girls, revealing a statistically significant difference for the sample.

Rivera (2011) conducted a cross-sectional study on 130 four-to-five-year-old preschoolers in Peralillo. As reported, $49.2 \%$ of the children presented caries, with a DMFT index of 2.4 (SD \pm 3.5 ). The $\mathrm{S}-\mathrm{OHI}$ for the complete sample was 1.4 (SD \pm 0.4 ). Gingivitis was reported in $9.2 \%$ of cases.

Accardi (2016) studied the prevalence of bad oral habits and their association with dentomaxillary anomalies in children aged three to six years in Dalcahue, Chiloé. The author found a general prevalence of bad oral habits of $78.3 \%$; the most frequent was mouth breathing (48.3\%), followed by onychophagia (36\%), labial interposition (30.3\%), digital suction and suction of a bottle ( $24.7 \%$ each), interposition of another object (5.6\%), and pacifier suction (3.3\%). However, Accardi did 
not observe statistically significant associations with dentomaxillary anomalies.

Aróstica and Carrillo (2016) found that the prevalence of malocclusions in preschool children in Viña del Mar was 54.35\% (95\% Cl [47.04\%-61.47\%]). There were no statistically significant differences by age, gender, or course. These results are similar to those obtained in several national and international studies, demonstrating that malocclusions constitute a public health problem that requires greater treatment coverage. In addition, from the 132 dentomaxillary anomalies found, the majority corresponded to transverse malocclusions, with crowding being the most frequent.

In the case of schoolchildren, Gómez etal. (2012) conducted a study on 116 children from 6 to 15 years old to determine the prevalence and severity of permanent tooth caries and some related risk factors on Easter Island. They reported that $38 \%$ of the sample presented caries in permanent teeth. The DMFT average was 1.19. Children's DMFT was 0.9 in Rapa Nui and 1.77 outside of Rapa Nui.

On the other hand, Fernández et al. (2011) conducted a cross-sectional study on 285 schoolchildren aged 12 years in municipalized educational establishments, comparing urban and rural populations in the Maule Region, Chile. The objective was to determine the prevalence of caries and factors associated with caries history and oral health self-perception. The prevalence of caries was $63.9 \%$, without significant differences by sex and residence area. Oral hygiene was associated with the area of residence and socioeconomic status (SES). The authors found that urban children have 5.6 times greater likelihood of having optimal hygiene than rural children.

There are several studies in Chile on malocclusions. Burgos et al. (2014) determined the prevalence of malocclusions in children and adolescents of Frutillar between 6 and 15 years, according to their occlusal characteristics. According to the sample, $96.2 \%$ of the students examined presented some type of malocclusion, with dentomaxillary discrepancy being observed more frequently in $67.4 \%$ of the cases. The prevalence of malocclusions found was higher than that reported by other studies.
On the other hand, Soto et al. (2007, 2014) sought to analyze the changes in oral morbidity trends. The researchers found that the prevalence of caries is $16.8 \%$ at two years, $49.6 \%$ at four years, $70.4 \%$ at six years, $62.5 \%$ at 12 years, and $73.9 \%$ at 15 years. In relation to the severity of caries, they found a DMFT of 0.5 at two years, a DMFT of 2.3 at four years, and a DMFT of 3.7 at six years in temporary dentition. In permanent dentition, the authors found a DMFT of 0.15 at six years, a DMFT of 1.9 at 12 years, and a DMFT of 3.0 at 15 years. Regarding gingivitis, they found a prevalence of $32.6 \%$ at two years, $45 \%$ at four years, $55.1 \%$ at six years, and $66.9 \%$ at 12 years. Regarding dentomaxillary anomalies, $33.3 \%$ presented some degree of anomaly at four years, $38.3 \%$ at six years, and $53 \%$ at 12 years. The authors conclude that a reduction of these diseases associated with the treatment and prevention plan of the current health system was achieved.

\section{DISCUSSION}

If we compare the Chilean figures with reviews made at the international level, we will find certain discrepancies in relation to the degree of increase of the most prevalent diseases. A systematic analysis of the global burden of diseases, injuries, and risk factors for the period 1990-2015 in 195 countries concludes that oral health has not improved in the last 25 years; oral conditions remain a major and growing global public health problem. While the standardized age prevalence of oral conditions remained relatively stable between 1990 and 2015, population growth and aging have led to a dramatic increase in the burden of untreated oral diseases worldwide. Greater efforts and, possibly, different approaches are needed if the international goals of oral health are to be achieved by 2020 . Similar conclusions are obtained by the systematic analysis carried out by Marcenes et al. (2013) on the global burden of oral conditions in 1990-2010, which indicated that oral conditions remained highly prevalent in 2010 , which affects collectively 3.9 billion people. Untreated caries in permanent teeth were the most frequent condition (overall prevalence of $35 \%$ for all ages combined), while severe periodontitis and untreated caries in deciduous teeth were the sixth and 10th most prevalent conditions, 
affecting $11 \%$ and $9 \%$ of the world population, respectively

(Kassebaum et al., 2015; Kassebaum et al., 2017).

Schwendicke et al. (2015) conducted a

systematic review and meta-analysis of socioeconomic inequality and caries. Within this research, studies investigating the association between social status (determined by educational or occupational background of the parents themselves, or income) and prevalence, experience, or incidence of caries were included. Eightythree studies found that at least one measure of caries was significantly higher in people with low SES, compared to people with higher SES, while only three studies found otherwise. The chances of having any caries experience were significantly greater in those with low educational or work history. Low SES is associated with an increased risk of having experiences of lesions or caries. This association could be stronger in developed countries. The established concepts of diagnosis and treatment may not take into account the uneven distribution of caries.

At the Chilean level, the various studies in specific localities have found a higher prevalence and severity of oral diseases. However, it is necessary to carry out a systematic evaluation to determine the prevalence and severity for each of the most prevalent oral diseases, as well as to identify the risk factors for the appearance of said diseases.

\section{REFERENCES}

Accardi K. Prevalencia de malos hábitos orales y su asociación con anomalías dentomaxilares en niños de 3 a 6 años. Comuna Dalcahue, Chiloé. (Tesis). Santiago: Universidad Andrés Bello; 2016.

Aróstica AN, Carrillo LG. Prevalencia de maloclusiones y hábitos orales disfuncionales en pre-escolares de establecimientos municipales de Viña del Mar. (Tesis). Santiago: Universidad Andrés Bello; 2016.

Bravo RL, Torres CF, Fierro MC, Pérez FMA. Oral Health Condition in Overweight Preschoolers Concepción, Chile. Int J Odontostomat. 2010; 4(3):267-70

Burgos D. Prevalence of Malocclusion in 6 to 15-year-old Children and Adolescents in Frutillar, Chile. Int J Odontostomat. 2014;8(1):13-9.

Espinoza-Espinoza G, Muñoz-Millán P, Vergara-González C, Atala-Acevedo C, Zaror C. Prevalence of early childhood caries in non-fluoridated rural areas of Chile. J Oral Res. 2016;5(8): 30713.

Fernández GC, Núñez FL, Díaz SN. Determinantes de salud oral en población de 12 años. Rev Clin Periodoncia Implantol Rehabil Oral. 2011;4(3):117-21.

Gómez GV, Cabello IR, Rodríguez MG, Urzúa Al, Silva SN, Phillips LM, Yévenes LI. Prevalencia de caries en escolares de 6 a
15 años, Isla de Pascua. Rev Clin Periodoncia Implantol Rehabil Oral. 2012;5(2):69-73.

Kassebaum NJ, Bernabé E, Dahiya B, Bhandari B, Murray CJ, Marcenes W. Global burden of untreated caries: a systematic review and metaregression. J Dent Res. 2015;94(5):650-8.

Kassebaum NJ, Smith AGC, Bernabé E, Fleming TD, Reynolds AE, Vos T, Murray CJL, Marcenes W; GBD 2015 Oral Health Collaborators. Global, Regional, and National Prevalence, Incidence, and Disability-Adjusted Life Years for Oral Conditions for 195 Countries, 1990-2015: A Systematic Analysis for the Global Burden of Diseases, Injuries, and Risk Factors. J Dent Res. 2017;96(4):380-7

Marcenes W, Kassebaum NJ, Bernabé E, Flaxman A, Naghavi M, Lopez A, Murray CJ. Global burden of oral conditions in 19902010: a systematic analysis. J Dent Res. 2013;92(7):592-7.

Ministerio de Salud. Análisis de situación de salud bucal en Chile. Santiago: Departamento de Salud Bucal División de Prevención y Control de Enfermedades; 2010.

Petersen PE, Bourgeois D, Ogawa H, Estupinan-Day S, Ndiaye C. The global burden of oral diseases and risks to oral health. Bull World Health Organ. 2005;83:661-9.

Rivera CA. Pre-school Child Oral Health in a Rural Chilean Community. Int J Odontostomat. 2011;5(1):83-6.

Schwendicke F, Dörfer CE, Schlattmann P, Foster Page L, Thomson WM, Paris S. Socioeconomic Inequality and Caries: A Systematic Review and Meta-Analysis. J Dent Res. 2015;94(1):10-8.

Soto L, Tapia R, Jara G, Rodríguez G, Urbina T. Diagnostico nacional de salud bucal del adolescente de 12 años y evaluación del grado de cumplimiento de los objetivos sanitarios de salud bucal 2000-2010. Santiago: Ediciones Universidad Mayor; 2007.

Soto L, Tapia R, et al: Ministerio de Salud de Chile. Diagnóstico Nacional de Salud Bucal de los niños y niñas de 6 años. Análisis por macrozona. Santiago, 2014.

Zaror SC, Pineda TP, Orellana CJJ. Prevalencia de caries temprana de la infancia y sus factores asociados en niños chilenos de 2 y 4 años. Int J Odontostomat. 2011;5(2):171-7.

Zaror SC, Muñoz MP, Sanhueza CA. Av Odontoestomatol. 2012;28(1):33-8.

Zaror SC, Sapunar ZJ, Muñoz NS, González CD. Asociación entre malnutrición por exceso con caries temprana de la infancia. Rev Chil Pediatr. 2014;85(4): 455-61. 